\title{
aB-crystallin stimulates VEGF secretion and tumor cell migration and correlates with enhanced distant metastasis in head and neck squamous cell carcinoma
}

Chantal van de Schootbrugge1, Johan Bussink², Paul N Span², Fred CGJ Sweep ${ }^{3}$, Reidar Grénman ${ }^{4}$, Hanneke Stegeman², Ger JM Pruijn ${ }^{1}$, Johannes HAM Kaanders ${ }^{2}$ and Wilbert C Boelens ${ }^{1,5^{*}}$

\begin{abstract}
Background: aB-crystallin is able to modulate vascular endothelial growth factor (VEGF) secretion. In many solid tumors VEGF is associated with angiogenesis, metastasis formation and poor prognosis. We set out to assess whether aB-crystallin expression is correlated with worse prognosis and whether this is related to VEGF secretion and cell motility in head and neck squamous cell carcinoma (HNSCC).
\end{abstract}

Methods: aB-crystallin expression was determined immunohistochemically in tumor biopsies of 38 HNSCC patients. Locoregional control (LRC) and metastasis-free survival (MFS) of the patients were analyzed in relation to aB-crystallin expression. Additionally, the effects of aB-crystallin knockdown on VEGF secretion and cell motility were studied in vitro.

Results: Patients with higher staining fractions of aB-crystallin exhibited a significantly shorter MFS (Log-Rank test, $p<0.005)$. Under normoxic conditions aB-crystallin knockdown with two different siRNAs in a HNSCC cell line reduced VEGF secretion 1.9-fold and 2.1-fold, respectively. Under hypoxic conditions, a similar reduction of VEGF secretion was observed, 1.9-fold and 2.2-fold, respectively. The effect on cell motility was assessed by a gap closure assay, which showed that aB-crystallin knockdown decreased the rate by which HNSCC cells were able to close a gap by 1.5 - to 2.0 -fold.

Conclusions: Our data suggest that aB-crystallin expression is associated with distant metastases formation in HNSCC patients. This association might relate to the chaperone function of aB-crystallin in mediating folding and secretion of VEGF and stimulating cell migration.

Keywords: CRYAB protein, HspB5, Vascular endothelial growth factor A, Cell movement, Neoplasm metastasis, Carcinoma, Squamous cell of head and neck

\footnotetext{
* Correspondence: W.Boelens@ncmls.ru.nl

'Department of Biomolecular Chemistry, Institute for Molecules and Materials and Nijmegen Center for Molecular Life Sciences, Radboud University Nijmegen, Nijmegen, The Netherlands

${ }^{5}$ Biomolecular Chemistry 271, NCMLS, Radboud University Nijmegen, PO Box 9101, 6500 HB, Nijmegen, The Netherlands

Full list of author information is available at the end of the article
} 


\section{Background}

The small heat shock protein $\alpha \mathrm{B}$-crystallin (HspB5) is expressed in several types of cancer, including head and neck squamous cell carcinomas (HNSCC) [1,2] and breast carcinomas [3-5]. The expression is often correlated with a poor prognosis, but the reason for this is not fully understood [6,7]. $\alpha \mathrm{B}$-crystallin plays a role in many different cellular processes such as proliferation, cell migration and apoptosis $[3,6,8]$. The expression of this protein is increased during various stresses, like heat shock and oxidative stress [9]. A well-known function of $\alpha \mathrm{B}$-crystallin is molecular chaperoning, allowing the prevention of aggregation of proteins [9]. Recently, it has been shown that $\alpha B$ crystallin chaperones the hypoxia-induced VEGF protein to the endoplasmic reticulum, leading to more properly folded and thus secreted VEGF $[10,11]$. VEGF is a major player involved in tumor angiogenesis [12] and increased VEGF secretion is often correlated with metastasis formation [13] and worse outcome for the patient [14].

HNSCC is the sixth most common cancer worldwide and accounts for $6 \%$ of all cancers [15]. The majority of these patients are treated with radiotherapy, alone or in combination with surgery or chemotherapy [16]. Based on the improved understanding of the molecular pathways underlying HNSCC, targeted drugs (e.g. EGFRspecific antibodies) and other modifications have been implemented in treatment protocols [16]. However, only a subset of patients profit from these combined modality strategies. Therefore, there is a great demand for biomarkers to customize treatment.

In the present study the value of $\alpha \mathrm{B}$-crystallin as a biomarker in HNSCC was investigated. $\alpha \mathrm{B}$-crystallin expression levels were immunohistochemically determined in HNSCC biopsies and correlated with clinicopathological characteristics and outcome. Moreover, the effect of knockdown of $\alpha B$-crystallin on VEGF secretion and cell migration was studied.

\section{Methods}

\section{Patients}

Biopsy material from a cohort of HNSCC patients with stage II to IV primary squamous cell carcinoma of the oral cavity, oropharynx, hypopharynx or larynx was used. The inclusion criteria of patients with HNSCC have been described before [17]. Approval from the ethics committee of Radboud University Nijmegen Medical Centre was obtained and all patients provided written informed consent. Of 13 patients no biopsy materials were left and were excluded from this study. The median duration of follow-up for all patients was 29 months and for surviving patients 85 months. During follow-up, LRC and MFS were registered.

\section{Immunohistochemical staining of aB-crystallin of HNSCC biopsies}

Oral cavity tumor sections [18] were incubated with 100fold diluted polyclonal rabbit $\alpha B$-crystallin antiserum [19] and subsequently stained with diaminobenzidine (DAB) according to a standard protocol. Sections of the 38 available biopsies $(5 \mu \mathrm{m})$ were mounted on poly-L-lysine coated slides, fixed for 10 minutes in acetone at $4^{\circ} \mathrm{C}$ and rehydrated in PBS. The sections were incubated overnight at $4^{\circ} \mathrm{C}$ with 100 -fold diluted $\alpha \mathrm{B}$-crystallin antiserum [19] and subsequently incubated for 30 minutes at $37^{\circ} \mathrm{C}$ with 600 -fold diluted goat- $\alpha$-rabbit-FabCy3 (Jackson Immuno Research Laboratories Inc) in PBS, for 45 minutes at $37^{\circ} \mathrm{C}$ with 10-fold diluted endothelium antibody PAL-E (Euro Diagnostica BV) in PAD, for 60 minutes at $37^{\circ} \mathrm{C}$ with 100-fold diluted chicken- $\alpha$-mouse Alexa647 (Molecular probes) in PBS and finally for 5 minutes at room temperature with $0.5 \mathrm{ng} / \mathrm{ml}$ Hoechst (Sigma) in PBS. Between the incubation steps, 3 times 2 minutes washing steps in PBS were performed. The sections were mounted using fluorostab (ProGen Biotechnik GmbH).

\section{Image acquisition}

Scanning of the tumor sections was performed with a fluorescence microscope (Axioskop, Zeiss) and a computer-controlled motorized stepping stage, using IPlab software (Scanalytics)[20]. Each section was completely scanned for $\alpha \mathrm{B}$-crystallin staining. The resulting grey scale images were subsequently binarized. Thresholds were set just above the background staining for each staining. Manually, the total tumor area was contoured, excluding surrounding tissue, large necrotic areas and artefacts. The percentage of $\alpha \mathrm{B}$-crystallin was determined as the tumor area positive for $\alpha \mathrm{B}$-crystallin relative to the total tumor area.

\section{Cell culture, siRNA treatment, hypoxia exposure and VEGF secretion measurement}

The HNSCC cell line, UT-SCC-5 (described in [21]), was maintained in DMEM + Glutamax $^{\mathrm{Tm}}$ (Invitrogen) supplemented with $10 \%$ fetal calf serum (Gibco-BRL) in a standard humidified $37^{\circ} \mathrm{C}$ incubator. At $40 \%$ confluency, cells were transfected using Lipofectamine 2000 Reagent according to the manufacturers' protocol (Invitrogen). The siRNAs used were si-Luciferase (siRNA LUC) as negative control, sequence: CGUACGCGGAAUACUUCGAdTdT, si- $\alpha$ B-crystallin1 (siRNA $\alpha B 1$ ) sequence: GCACCCAGC UGGUUUGACAdTdT and si- $\alpha$ B-crystallin2 (siRNA $\alpha B 2$ ) sequence: CCCUGAGUCCCUUCUACCUdTdT. After 5 hours, cells were reseeded $\left(9.0 \times 10^{3}\right.$ cells in $0.3 \mathrm{~cm}^{2}$ wells in 12-fold, for VEGF secretion measurements, and $2.5 \times 10^{5}$ cells in $10 \mathrm{~cm}^{2}$ wells in 4-fold, for RNA expression measurements (see below)). Hypoxia treatment was performed 
24 hours after siRNA transfection cells in a humidified $37^{\circ} \mathrm{C}$ H35 Hypoxystation (Don Whitley Scientific) with $0.1 \% \mathrm{O}_{2}$. Cells cultured under normoxic (6-fold) and hypoxic (6-fold) conditions were maintained for 48 hours. The culture media of the samples were collected and VEGF levels were determined using a quantitative enzyme-linked immunosorbent assay (ELISA). The details of this assay have been described previously by Span and coworkers [22]. The assay is based on the combination of four polyclonal antibodies raised in four different animal species, duck, chicken, rabbit and goat, and are employed in a sandwich assay format. The assay measures $V_{E G F} 165$ and $V_{E G F}$ 121, the main isoforms of VEGF. There is no cross-reactivity with VEGF B, VEGF $\mathrm{C}$ and VEGF D $[22,23]$.

\section{Gap closing assay}

The HNSCC cell line UT-SCC-15 [21] was transfected with siRNA as described above. Twenty-four hours after transfection, cells were seeded at $1.0 \times 10^{5}$ cells per side of the Culture-Inserts (Ibidi, $\mathrm{N}=6$ per condition). For quantitative RT-PCR, $0.5 \times 10^{6}$ cells were seeded in parallel in 10 $\mathrm{cm}^{2}$ wells $(\mathrm{N}=5) .24$ Hours later cells were washed with PBS, fresh medium was added and the insert was removed. Time lapse imaging was performed for 24 hours in a microscope stage incubator (Oko-Lab) on a Nikon DiaPhot microscope equipped with a Hamamatsu C848405G digital camera. Images were taken every 10 min using TimeLapse Software (Oko-Lab), version 2.7, with a 10x objective. Analysis of gap closing was performed using TScratch [24].

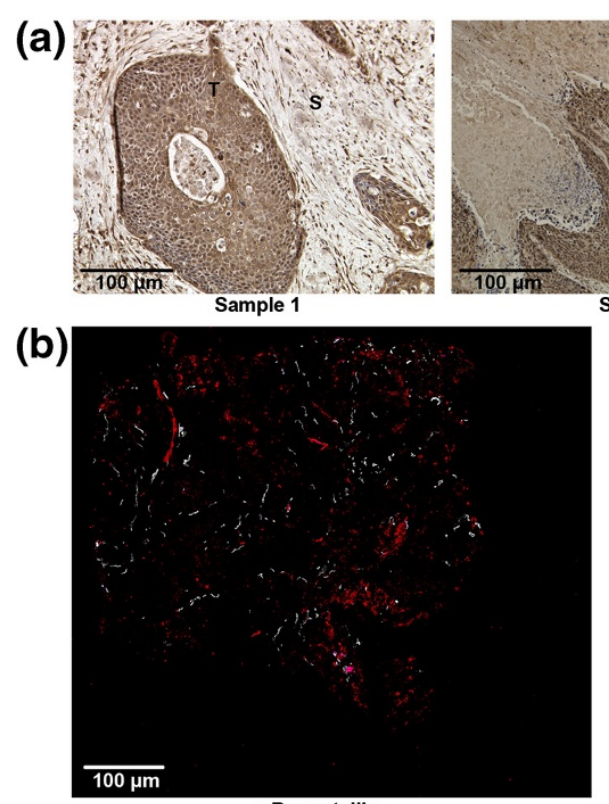

(c)

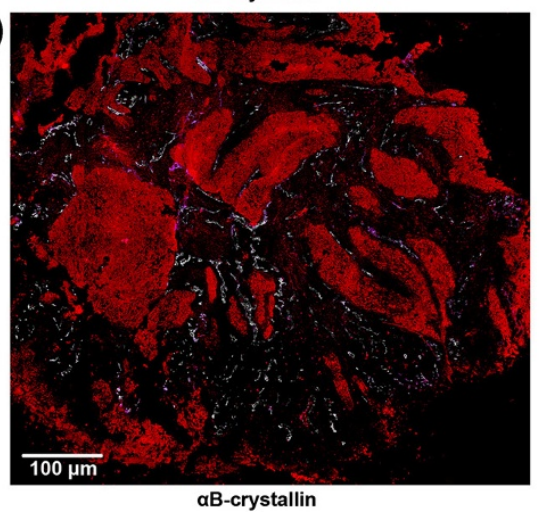

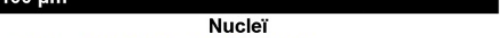

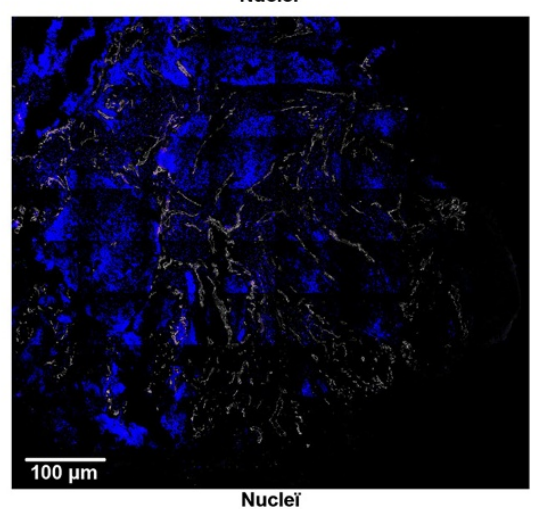

Figure 1 Immunohistochemical staining of tumor tissues with polyclonal anti-aB-crystallin antibody. DAB staining of three oral cavity tumor sections. Tumor cells are indicated with T, surrounding stromal cells with S. (a). Immunofluorescent staining of biopsies with low aB-crystallin expression (red, b left panel) and high aB-crystallin expression (red, c left panel) and the corresponding Hoechst stainings (blue, $\mathbf{b}$ and $\mathbf{c}$ right panels). Blood vessels are indicated in white (b and $\mathbf{c}$ ). 


\section{RNA analysis by quantitative PCR}

Total RNA from UT-SCC-5 and UT-SCC-15 cell lysates was extracted using standard Trizol isolation. After DNAse I treatment (Amplification grade, Invitrogen) mRNAs were reverse transcribed using oligo(dT) primers and the Reverse Transcription System (Promega) according to manufacturer's protocol starting with $1 \mu \mathrm{g}$ of RNA in a total volume of $20 \mu \mathrm{l}$. Subsequently quantitative PCR reactions were performed with $10 \mu \mathrm{l}$ Power SYBR Green (Applied BioSystems), $5 \mu \mathrm{M}$ of primers and $2 \mu \mathrm{l} \mathrm{cDNA}$ in a total volume of $20 \mu \mathrm{l}$. The sequence of the used $\alpha \mathrm{B}$-crystallin primers is: $5^{\prime}$-ATCTTCTTTTGCGTCGCCAG-3' and $5^{\prime}$-TTCCCCATGGTGTCTGAGC- $3^{\prime}$, and of the GAPD H primers: $5^{\prime}$-GATTGAGGTGCATGGAAAAC- $3^{\prime}$ and $5^{\prime}$-AGGACCCCATCAGATGACAG- $3^{\prime}$. The fluorescent signal intensities were recorded with the ABI Prism 7000 system (Applied Biosystems). Samples were kept for 10 minutes at $95^{\circ} \mathrm{C}$, followed by 40 cycles of $15 \mathrm{sec}-$ onds at $95^{\circ} \mathrm{C}$ and 1 minute at $60^{\circ} \mathrm{C}$. Data analysis was performed with 7000 System SDS software (Applied BioSystems).

\section{Statistics}

Statistical analyses were performed using Graphpad Prism 5.00 software. To test for differences in $\alpha \mathrm{B}$-crystallin expression using binary patient data, the unpaired $t$-test was used. For survival analyses, receiver operating characteristic (ROC) curves were made to determine the cut-off value with the highest sensitivity and specificity for discriminating between patients with or without locoregional recurrence (LRR) or distant metastasis with at least 24 months of follow-up or an LRR or distant metastatic event before that. Survival rates were calculated starting at the date of diagnosis. The Kaplan-Meier method and the log-rank test were used to test for differences in LRC and MFS rates in all patients. P-values below 0.05 were considered a priori to indicate a significant difference. Differences in VEGF secretion and gap closure speed were tested using One-way ANOVA and Tukey's Multiple Comparison Test.

\section{Results}

The presence of $\alpha B$-crystallin in the tumors was analyzed by immunohistological staining. In most tumors cells $\alpha B$-crystallin could be detected. In stromal cells, no or only very low levels of nuclear staining were found (Figure 1a). The $\alpha \mathrm{B}$-crystallin expression was determined in 38 primary HNSCC biopsies, which were histologically confirmed to contain tumor tissue [17]. The characteristics of the tumors at the time point of biopsy collection are listed in Table 1. To quantify the fraction of the tumor section expressing $\alpha B$-crystallin, fluorescently labeled secondary antibodies were used and the images were analyzed with
Table 1 Characteristics of $\mathbf{3 8}$ head and neck squamous cell carcinomas

\begin{tabular}{lc}
\hline Characteristics & Number of biopsies \\
\hline Site of tumor & 1 \\
Oral cavity & 12 \\
Hypopharynx & 15 \\
Larynx & 10 \\
Oropharynx & \\
$T$ classification & 1 \\
1 & 13 \\
2 & 16 \\
3 & 8 \\
4 & \\
N classification & 10 \\
0 & 10 \\
1 & 18 \\
2 & \\
M classification & 38 \\
0 & \\
Differentiation grade & \\
1 & 2 \\
2 & 21 \\
3 & 14 \\
Unknown & 1 \\
\hline
\end{tabular}

a digital image analysis system. Only, the tumor area was used for the analysis by excluding the surrounding stromal tissue, large necrotic areas and artifacts. The results showed that the $\alpha \mathrm{B}$-crystallin expressing tumor areas varied from 0 to $69 \%$. Examples of biopsies having marginal and extensive $\alpha B$-crystallin expression are shown in Figure $1 \mathrm{~b}$ and $\mathrm{c}$.

\section{aB-crystallin expression in HNSCC biopsies is associated with distant metastasis}

Patients with at least 24 months of event-free follow up or with a locoregional recurrence (LRR) or distant metastatic event before 24 months were dichotomized in groups with and without LRR $(\mathrm{N}=16$ and $\mathrm{N}=12$, respectively), or with and without metastasis $(\mathrm{N}=17$ and $\mathrm{N}=10$, respectively). Figure 2 shows that the mean percentage of the tumor area expressing $\alpha \mathrm{B}$-crystallin was not significantly different between biopsies from patients with or without LRR (Figure 2a). However, the mean percentage of the tumor area expressing $\alpha \mathrm{B}$-crystallin was significantly higher in biopsies from patients who developed distant metastasis during follow up as compared to those without (two-tailed unpaired $t$-test, $\mathrm{p}<$ 0.05 , Figure $2 \mathrm{~b}$ ). The highest sensitivity and specificity 


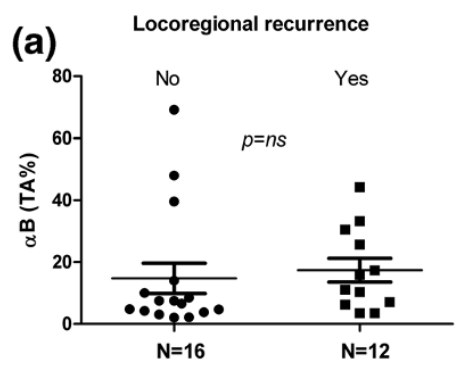

(c)

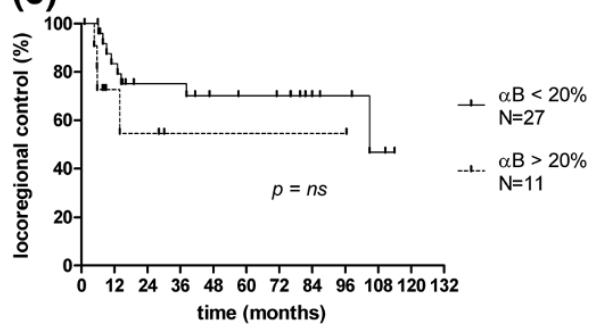

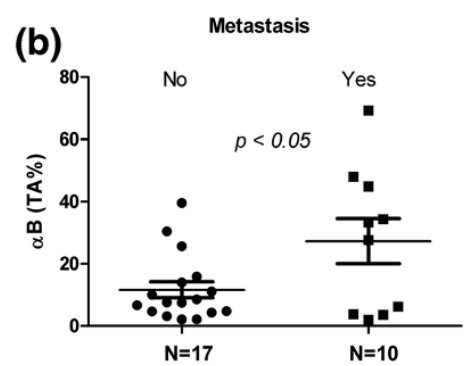

(d)

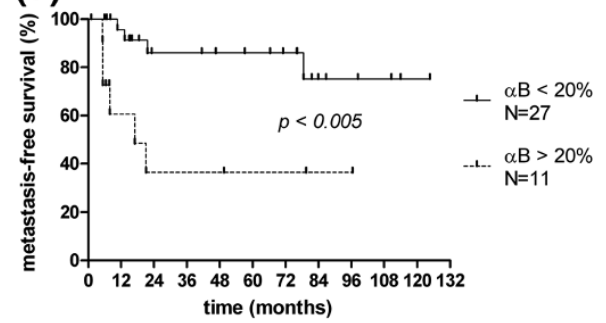

Figure 2 Relation between aB-crystallin expression and locoregional recurrence and metastasis. aB-crystallin expression per biopsy and the mean $\mathrm{aB}$-crystallin expression of each group with standard error of the mean (SEM) in biopsies from patients without or with locoregional recurrence (a) or metastasis (b) and Kaplan-Meier analysis of locoregional control (c) and metastasis-free survival (d) for patients with high ( $>20 \%$ of tumor area) and low ( $<20 \%$ of tumor area) aB-crystallin expression. TA: Tumor area, ns: not significant.

for discriminating between patients with or without metastasis was determined by receiver operating characteristic (ROC) curve to be at a cut-off value of $20 \%$. At this cut-off value the Kaplan-Meier estimates for LRC did not show any significant differences (Figure 2c), and the same result was obtained with other cut-off values (results not shown). For MFS a significant difference was observed (Log-Rank, $\mathrm{p}<0.005$, Figure $2 \mathrm{~d}$ ), which was especially clear after 22 months; at that time point MFS was $86 \%$ for the patients with relatively low fractions of tumor area expressing $\alpha \mathrm{B}$-crystallin, whereas this was only $36 \%$ for the patients with extensive $\alpha B$ crystallin expression in the tumors. These results suggest that the levels of $\alpha \mathrm{B}$-crystallin expression inversely correlate with MFS.

\section{aB-crystallin expression enhances VEGF secretion}

The recently reported involvement of $\alpha B$-crystallin in VEGF production prompted us to investigate the effects of $\alpha B$-crystallin expression on VEGF secretion by HNSCC cells. For these experiments the HNSCC cell line UT-SCC- 5 was used and the levels of $\alpha \mathrm{B}$-crystallin were reduced by siRNA-mediated knock-down. Two distinct $\alpha \mathrm{B}$-crystallin siRNAs, $\alpha \mathrm{B} 1$ and $\alpha \mathrm{B} 2$, resulted in a 1.3-fold and 1.8-fold reduction of $\alpha B$-crystallin mRNA levels, respectively (Figure 3a). Downregulation of $\alpha B$ -
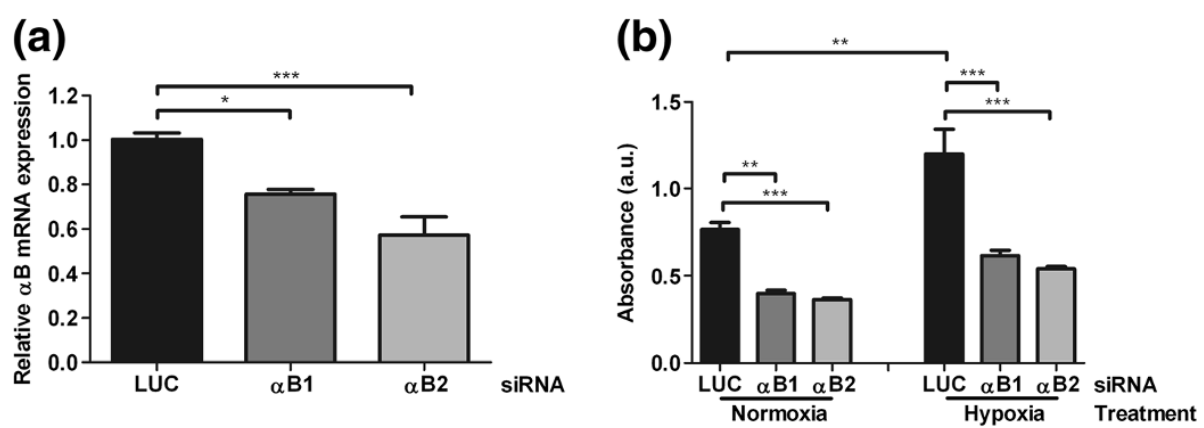

Figure 3 Influence of aB-crystallin knock-down on VEGF secretion. Knockdown of aB-crystallin mRNA expression in UT-SCC-5 cells by two different siRNAs, aB1 and aB2, compared to negative control siRNA LUC (Luciferase) as measured by quantitative PCR (a). VEGF secretion levels in UT-SCC-5 cells transfected with the AB1, aB2 or LUC siRNA under normoxic and hypoxic conditions determined by ELISA (b). Statistical analysis was performed using One-way ANOVA and Tukey's Multiple Comparison Test. ${ }^{* *} \mathrm{P}<0.001,{ }^{* *} 0.001<\mathrm{P}<0.01,{ }^{*} 0.01<\mathrm{P}<0.05$; a.u: absorbance units. 
crystallin significantly decreased VEGF secretion (1.9fold and 2.1-fold reduction, respectively). Since hypoxia leads to elevated VEGF production, we next assessed the effects of $\alpha \mathrm{B}$-crystallin knock-down under hypoxic conditions. Indeed, VEGF secretion appeared to be increased in UT-SCC-5 cells by hypoxia (Figure 3b, 1.6fold) and also under these conditions $\alpha \mathrm{B}$-crystallin depletion resulted in decreased VEGF expression (1.9-fold and 2.2-fold reduction, respectively). These results show that $\alpha \mathrm{B}$-crystallin expression can affect VEGF secretion both at normoxia and hypoxia.

\section{Effect of aB-crystallin expression on cell migration}

The association of $\alpha B$-crystallin expression with metastasis may also be due to effects on cell motility [3]. To investigate whether motility of HNSCC cells is affected by reduced $\alpha \mathrm{B}$-crystallin a gap closure assay was applied. Since the UT-SCC-5 cells were easily damaged during gap preparation, disturbing migration, the related cell line UT-SCC-15 was used. Also in this HNSCC cell line $\alpha B$-crystallin mRNA levels could be diminished by siRNA-mediated knock-down, although the efficiency appeared to be much higher than that in the UT-SCC-5 cells (Figure 4a). Depletion of $\alpha B$-crystallin resulted in decreased gap closure rates compared to mock treated cells (Figure $4 \mathrm{~b}$ ). The cell migration rate was reduced 2.0-fold from and 1.5-fold after treatment with the siRNA $\alpha B 1$ and $\alpha B 2$, respectively (Figure $4 c$ ).

\section{Discussion}

Here, we show that $\alpha \mathrm{B}$-crystallin expression in HNSCC tumors correlates with MFS, but not with LRC. Clues for the mechanism by which $\alpha \mathrm{B}$-crystallin might affect distant metastasis formation in patients were obtained by the depletion of $\alpha B$-crystallin in HNSCC cell lines, which showed that both VEGF secretion and cell motility were decreased when $\alpha \mathrm{B}$-crystallin expression was reduced.

Previously, two studies have addressed the prognostic value of $\alpha \mathrm{B}$-crystallin in HNSCC. Chin and coworkers have shown that $\alpha \mathrm{B}$-crystallin is a marker for poor prognosis [1], which is substantiated by our data. However, they noted that none of the patients lacking $\alpha \mathrm{B}$-crystallin had LRR, while $37 \%$ of the patients with tumors stained positive for $\alpha B$-crystallin had LRR. In the current study, the difference in prognosis was mainly caused by a higher rate of distant metastasis in the high $\alpha \mathrm{B}$-crystallin group and not by a difference in LRR. Boslooper and colleagues did not find $\alpha \mathrm{B}$-crystallin to be a prognostic marker for HNSCC [2]. These researchers observed the highest concentrations of $\alpha \mathrm{B}$-crystallin in the centre of tumor cell nests and not the more diffuse localization observed in this study and the study of Chin and coworkers [1]. This difference in $\alpha \mathrm{B}$-crystallin localization

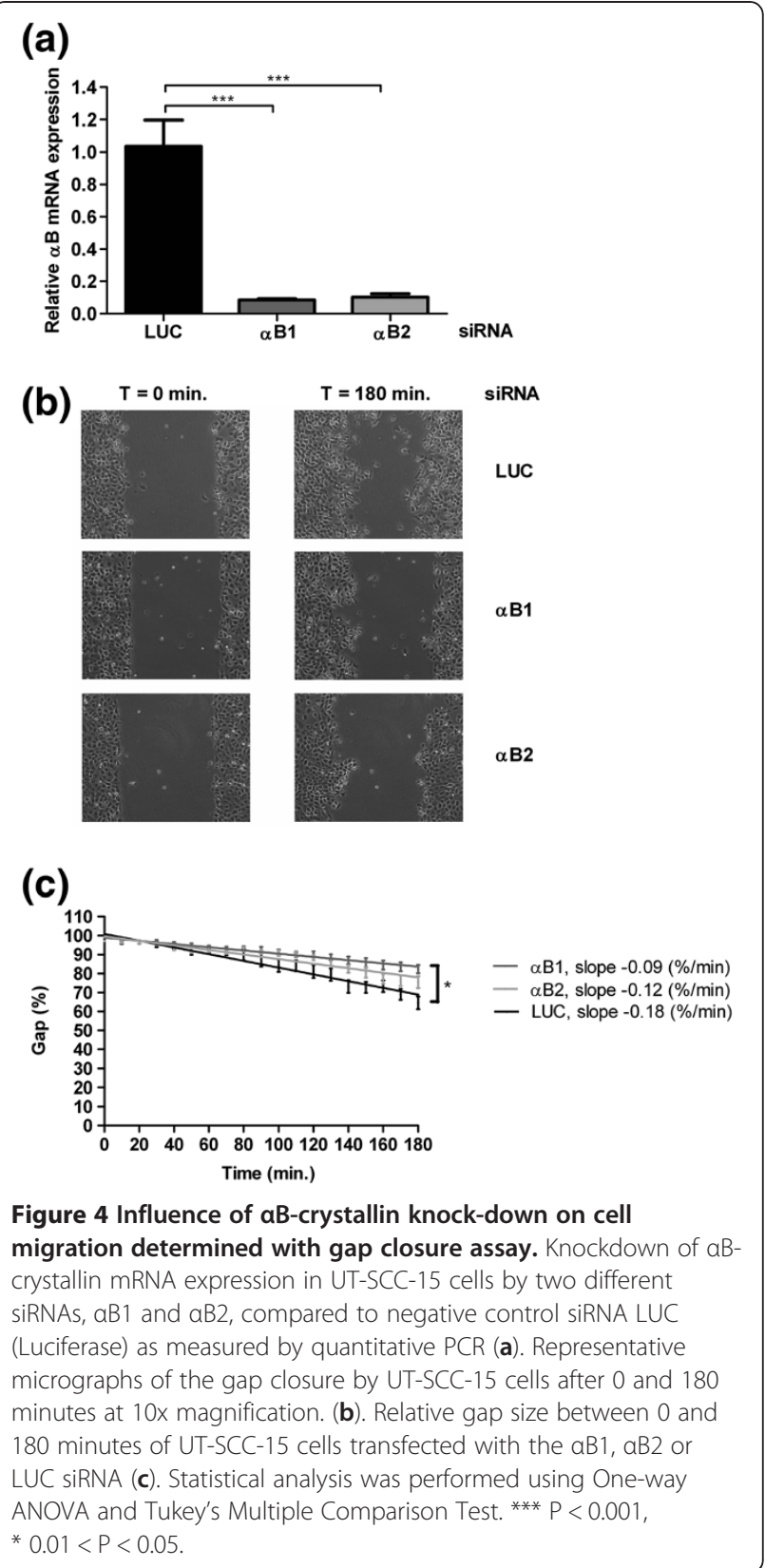

may have been caused by a difference in staining procedure and could be the reason why this study led to a different conclusion.

$\alpha B$-crystallin was also found to be associated with a poor prognosis in several other types of cancers, such as breast cancer $[3-5,25,26]$ and was downregulated in a breast cancer cell line by breast cancer metastasis suppressor 1, which specifically suppresses metastasis [27]. $\alpha \mathrm{B}$-crystallin is a molecular chaperone able to prevent protein aggregation and can confer protection to cells under stress conditions. $\alpha \mathrm{B}$-crystallin inhibits apoptosis in response to different anti-cancer agents, such as 
DNA-damaging drugs, TNF $\alpha$ and Fas ligand [6] and has been shown to be a predictor of resistance to chemotherapy [28]. However, since our data do not support an association of $\alpha \mathrm{B}$-crystallin expression with local recurrence after treatment of the patients, the cytoprotective activity is likely not the sole reason why $\alpha \mathrm{B}$-crystallin is associated with poor prognosis.

Metastasis formation occurs via a series of steps, also known as the "metastatic cascade" [29]. One of the factors associated with metastatic spread is VEGF $[30,31]$. Several studies have demonstrated roles for $\alpha B$-crystallin in VEGF-dependent angiogenesis [32]. Tumor vasculature in $\alpha B$-crystallin-deficient mice displays high levels of endothelial apoptosis and decreased vessel formation. $\alpha B$-crystallin has been shown to associate with VEGF-A (the most well-known member of the VEGF protein family) $[8,33]$ and colocalizes with VEGF at the endoplasmic reticulum [11]. Furthermore, VEGF-A expression remained low in $\alpha \mathrm{B}$-crystallindeficient mice during retinal revascularization after artificially-induced retinopathy [10]. Here we have shown that in a HNSCC cell line $\alpha \mathrm{B}$-crystallin is also involved in secretion of VEGF and in this way may influence tumorigenic blood vessel formation and metastasis formation in HNSCC. For the growth of metastatic tumors in lymph nodes neoangiogenesis is not absolutely needed $[34,35]$, which might explain why no correlation was found between $\alpha \mathrm{B}$-crystallin expression and LRC.

Migration-associated proteins may also correlate with worse outcome, as has been shown for patients with squamous cell carcinoma of the tongue [36]. $\alpha \mathrm{B}$-crystallin can affect cell migration as well. Overexpression of $\alpha \mathrm{B}$-crystallin led to higher cell motility in several studies [3,25,37]. Here we have shown that depletion of $\alpha \mathrm{B}$-crystallin decreased the motility of UT-SCC cells, indicating also in these types of cells $\alpha \mathrm{B}$-crystallin may affect cell migration. VEGF also plays a role in cell migration [38], potentially by enhancing invadopodia formation [39]. The effect of $\alpha \mathrm{B}$-crystallin on cell migration may thus be mediated by VEGF, although other mechanisms are also possible, as for example by the influence of $\alpha B$-crystallin on actin filaments dynamics $[39,40]$. Further research is needed to reveal the molecular mechanisms by which $\alpha \mathrm{B}$-crystallin affects cell migration.

\section{Conclusions}

High $\alpha \mathrm{B}$-crystallin expression is associated with metastasis formation in HNSCC but not with locoregional recurrence. $\alpha \mathrm{B}$-crystallin could be a useful biomarker to help fine-tune treatment, possibly by targeting $\alpha B$-crystallin-induced VEGF secretion or cell motility. Validation in a larger HNSCC cohort is required to confirm the significance of this finding.

\section{Abbreviations}

HNSCC: Head and neck squamous cell carcinoma; LRC: Locoregional control; LRR: Locoregional recurrence; MFS: Metastasis-free survival; ROC: Receiver operating characteristic; VEGF: Vascular endothelial growth factor.

\section{Competing interests}

The authors have no competing interest to declare.

\section{Authors' contributions}

CS participated in the study concept and design, data acquisition of all figures, data analysis and interpretation, statistical analysis, manuscript preparation and editing. JB participated in the study concept and design and manuscript editing. PS participated in study design, data analysis and interpretation, statistical analysis and manuscript editing. FS participated in data acquisition of the VEGF figure and manuscript reviewing. RG participated in data acquisition of the VEGF and cell motility figure and in manuscript reviewing. HS participated in data acquisition of the VEGF and cell motility figure. GP participated in study concept and manuscript reviewing. JK participated in study concept and design and manuscript editing. WB participated in study concept and design, data analysis and interpretation and manuscript editing. All authors read and approved the final manuscript.

\section{Acknowledgements}

We would like to thank E.G. Troost for provision of the tumors, W.J. Peeters and J. Lok for staining of the HNSCC tumors and biopsies, J.J.T.M. Heuvel for the VEGF quantification, I.J. Hoogsteen for helping with the survival analysis and the Dutch Cancer Society (KWF) for funding (grant KUN 2007-3864).

\section{Author details}

${ }^{1}$ Department of Biomolecular Chemistry, Institute for Molecules and Materials and Nijmegen Center for Molecular Life Sciences, Radboud University Nijmegen, Nijmegen, The Netherlands. '2Department of Radiation Oncology, Radboud University Nijmegen Medical Centre, PO Box 9101, 6500 HB, Nijmegen, The Netherlands. ${ }^{3}$ Department of Laboratory Medicine, Radboud University Nijmegen Medical Centre, PO Box 9101, 6500 HB, Nijmegen, The Netherlands. ${ }^{4}$ Department of Otorhinolaryngology-Head and Neck Surgery, Turku University Hospital, PO Box 52, Fl-20521, Turku, Finland. ${ }^{5}$ Biomolecular Chemistry 271, NCMLS, Radboud University Nijmegen, PO Box 9101, 6500 HB, Nijmegen, The Netherlands.

\section{Received: 25 October 2012 Accepted: 8 March 2013}

Published: 18 March 2013

\section{References}

1. Chin D, Boyle GM, Williams RM, Ferguson K, Pandeya N, Pedley J, Campbell CM, Theile DR, Parsons PG, Coman WB: aB-crystallin, a new independent marker for poor prognosis in head and neck cancer. Laryngoscope 2005, 115:1239-1242.

2. Boslooper K, King-Yin LA, Gao J, Weinstein S, Johnson N: The clinicopathological roles of aB-crystallin and p53 expression in patients with head and neck squamous cell carcinoma. Pathology 2008, 40:500-504.

3. Moyano JV, Evans JR, Chen F, Lu M, Werner ME, Yehiely F, Diaz LK, Turbin D, Karaca G, Wiley E, Nielsen TO, Perou CM, Cryns VL: aB-crystallin is a novel oncoprotein that predicts poor clinical outcome in breast cancer. J Clin Invest 2006, 116:261-270.

4. Sitterding SM, Wiseman WR, Schiller CL, Luan C, Chen F, Moyano JV, Watkin WG, Wiley EL, Cryns VL, Diaz LK: aB-crystallin: a novel marker of invasive basal-like and metaplastic breast carcinomas. Ann Diagn Pathol 2008, 12:33-40.

5. Kim HS, Lee Y, Lim YA, Kang HJ, Kim LS: aB-Crystallin is a novel oncoprotein associated with poor prognosis in breast cancer. J. Breast Cancer 2011, 14:14-19.

6. Arrigo AP, Simon S, Gibert B, Kretz-Remy C, Nivon M, Czekalla A, Guillet D, Moulin M, Diaz-Latoud C, Vicart P: Hsp27 (HspB1) and aB-crystallin (HspB5) as therapeutic targets. FEBS Lett 2007, 581:3665-3674.

7. Gruvberger-Saal SK, Parsons R: Is the small heat shock protein aB-crystallin an oncogene? J Clin Invest 2006, 116:30-32. 
8. Ghosh JG, Shenoy AK Jr, Clark Jl: Interactions between important regulatory proteins and human aB crystallin. Biochemistry 2007, 46:6308-6317.

9. van de Schootbrugge C, Boelens WC: Introduction to Small Heat Shock Proteins. In Small Stress Proteins and Human Diseases. Edited by Simon S, Arrigo AP. Nova Science Publishers. Protein Science and Engineering; 2010:1-27

10. Kase S, He S, Sonoda S, Kitamura M, Spee C, Wawrousek E, Ryan SJ, Kannan $R$, Hinton DR: aB-crystallin regulation of angiogenesis by modulation of VEGF. Blood 2010, 115:3398-3406.

11. Kerr BA, Byzova TV: aB-crystallin: a novel VEGF chaperone. Blood 2010, 115:3181-3183.

12. Martiny-Baron G, Marme D: VEGF-mediated tumour angiogenesis: a new target for cancer therapy. Curr Opin Biotechnol 1995, 6:675-680.

13. Hu Z, Fan C, Livasy C, He X, Oh DS, Ewend MG, Carey LA, Subramanian S, West R, Ikpatt F, Olopade Ol, van de Rijn M, Perou CM: A compact VEGF signature associated with distant metastases and poor outcomes. BMC Med 2009, 7:9

14. Bremnes RM, Camps C, Sirera R: Angiogenesis in non-small cell lung cancer: the prognostic impact of neoangiogenesis and the cytokines VEGF and bFGF in tumours and blood. Lung Cancer 2006, 51:143-158

15. Parkin DM, Bray F, Ferlay J, Pisani P: Global cancer statistics, 2002 CA Cancer J Clin 2005, 55:74-108.

16. Leemans $\mathrm{CR}$, Braakhuis BJ, Brakenhoff $\mathrm{RH}$ : The molecular biology of head and neck cancer. Nat Rev Cancer 2011, 11:9-22.

17. Hoogsteen IJ, Marres HA, Wijffels Kl, Rijken PF, Peters JP, van den Hoogen FJ, Oosterwijk E, van der Kogel AJ, Kaanders JH: Colocalization of carbonic anhydrase 9 expression and cell proliferation in human head and neck squamous cell carcinoma. Clin Cancer Res 2005, 11:97-106.

18. Troost EG, Bussink J, Slootweg PJ, Peeters WJ, Merkx MA, van der Kogel AJ, Oyen WJ, Kaanders JH: Histopathologic validation of 3'-deoxy-3'-18Ffluorothymidine PET in squamous cell carcinoma of the oral cavity. J Nucl Med 2010, 51:713-719.

19. van de Klundert FA, Gijsen ML, van den IJssel PR, Snoeckx LH, de Jong WW aB-crystallin and hsp25 in neonatal cardiac cells--differences in cellular localization under stress conditions. Eur J Cell Biol 1998, 75:38-45.

20. Rijken PF, Bernsen HJ, Peters JP, Hodgkiss RJ, Raleigh JA, van der Kogel AJ: Spatial relationship between hypoxia and the (perfused) vascular network in a human glioma xenograft: a quantitative multi-parameter analysis. Int J Radiat Oncol Biol Phys 2000, 48:571-582.

21. Yaromina A, Zips D, Thames HD, Eicheler W, Krause M, Rosner A, Haase M Petersen C, Raleigh JA, Quennet V, Walenta S, Mueller-Klieser W, Baumann M: Pimonidazole labelling and response to fractionated irradiation of five human squamous cell carcinoma ( $\mathrm{hSCC}$ ) lines in nude mice: the need for a multivariate approach in biomarker studies. Radiother Oncol 2006, 81:122-129.

22. Span PN, Grebenchtchikov N, Geurts-Moespot J, Westphal JR, Lucassen AM, Sweep CG: EORTC Receptor and Biomarker Study Group Report: a sandwich enzyme-linked immunosorbent assay for vascular endothelial growth factor in blood and tumor tissue extracts. Int J Biol Markers 2000, 15:184-191.

23. Zusterzeel PL, Span PN, Dijksterhuis MG, Thomas CM, Sweep FC, Massuger LF: Serum vascular endothelial growth factor: a prognostic factor in cervical cancer. J Cancer Res Clin Oncol 2009, 135:283-290.

24. Geback T, Schulz MM, Koumoutsakos P, Detmar M: TScratch: a novel and simple software tool for automated analysis of monolayer wound healing assays. Biotechniques 2009, 46:265-274.

25. Goplen D, Bougnaud S, Rajcevic U, Boe SO, Skaftnesmo KO, Voges J, Enger PO, Wang J, Tysnes BB, Laerum OD, Niclou S, Bjerkvig R: aB-crystallin is elevated in highly infiltrative apoptosis-resistant glioblastoma cells. Am J Pathol 2010, 177:1618-1628.

26. Tang Q, Liu YF, Zhu XJ, Li YH, Zhu J, Zhang JP, Feng ZQ, Guan XH: Expression and prognostic significance of the aB-crystallin gene in human hepatocellular carcinoma. Hum Pathol 2009, 40:300-305.

27. Cicek M, Samant RS, Kinter M, Welch DR, Casey G: Identification of metastasis-associated proteins through protein analysis of metastatic MDA-MB-435 and metastasis-suppressed BRMS1 transfected-MDA-MB435 cells. Clin Exp Metastasis 2004, 21:149-157.

28. Ivanov O, Chen F, Wiley EL, Keswani A, Diaz LK, Memmel HC, Rademaker A Gradishar WJ, Morrow M, Khan SA, Cryns VL: aB-crystallin is a novel predictor of resistance to neoadjuvant chemotherapy in breast cancer. Breast Cancer Res Treat 2008, 111:411-417.

29. Geiger TR, Peeper DS: Metastasis mechanisms. Biochim Biophys Acta 2009, 1796:293-308.

30. Hicklin DJ, Ellis LM: Role of the vascular endothelial growth factor pathway in tumor growth and angiogenesis. J Clin Oncol 2005, 23:1011-1027.

31. Christopoulos A, Ahn SM, Klein JD, Kim S: Biology of vascular endothelial growth factor and its receptors in head and neck cancer: beyond angiogenesis. Head Neck 2011, 33:1220-1229.

32. Dimberg A, Rylova S, Dieterich LC, Olsson AK, Schiller P, Wikner C, Bohman S, Botling J, Lukinius A, Wawrousek EF, Claesson-Welsh L: aB-crystallin promotes tumor angiogenesis by increasing vascular survival during tube morphogenesis. Blood 2008, 111:2015-2023.

33. Ruan Q, Han S, Jiang WW, Boulton ME, Chen ZJ, Law BK, Cai J: aB-crystallin, a effecter of unfolded protein response, confers anti-VEGF resistance to breast cancer via maintenance of intracrine VEGF in endothelial cells. Mol Cancer Res 2011, 9:1632-1643.

34. Naresh KN, Nerurkar AY, Borges AM: Angiogenesis is redundant for tumour growth in lymph node metastases. Histopathology 2001, 38:466-470.

35. Kyzas PA, Stefanou D, Batistatou A, Agnantis NJ: Prognostic significance of VEGF immunohistochemical expression and tumor angiogenesis in head and neck squamous cell carcinoma. J Cancer Res Clin Oncol 2005, 131:624-630.

36. Endo K, Shirai A, Furukawa M, Yoshizaki T: Prognostic value of cell motility activation factors in patients with tongue squamous cell carcinoma. Hum Pathol 2006, 37:1111-1116.

37. Ho PY, Chueh SC, Chiou SH, Wang SM, Lin WC, Lee IL, Yang HY, Peng HC, Lai MK: $A B$-Crystallin in clear cell renal cell carcinoma: Tumor progression and prognostic significance. Oncol: Urol; 2012

38. Benke EM, Ji Y, Patel V, Wang $H$, Miyazaki $H$, Yeudall WA: VEGF-C contributes to head and neck squamous cell carcinoma growth and motility. Oral Oncol 2010, 46:e19-e24

39. Lucas JT Jr, Salimath BP, Slomiany MG, Rosenzweig SA: Regulation of invasive behavior by vascular endothelial growth factor is HEF1dependent. Oncogene 2010, 29:4449-4459.

40. Singh BN, Rao KS, Ramakrishna T, Rangaraj N, Rao C: Association of aBcrystallin, a small heat shock protein, with actin: role in modulating actin filament dynamics in vivo. $J \mathrm{Mol}$ Biol 2007, 366:756-767.

doi:10.1186/1471-2407-13-128

Cite this article as: van de Schootbrugge et al: aB-crystallin stimulates VEGF secretion and tumor cell migration and correlates with enhanced distant metastasis in head and neck squamous cell carcinoma. BMC Cancer 2013 13:128.

\section{Submit your next manuscript to BioMed Central and take full advantage of:}

- Convenient online submission

- Thorough peer review

- No space constraints or color figure charges

- Immediate publication on acceptance

- Inclusion in PubMed, CAS, Scopus and Google Scholar

- Research which is freely available for redistribution 